\title{
Thermally treated aluminium waste-filings, a low cost and efficient adsorbent for phosphorus removal from water
}

\author{
Qasemi M. ${ }^{1}$, Hosseini-Bandegharaei A. $^{2,3}$, Afsharnia M. ${ }^{1}$, Najafpoor A.A. ${ }^{4,5}$, Ivanets A. ${ }^{6}$, López-Delgado A. ${ }^{7}$, Alakhras F. ${ }^{8}$ and \\ Shams M. ${ }^{4,5},{ }^{*}$ \\ ${ }^{1}$ Department of Environmental Health Engineering, School of public Health, Gonabad University of Medical Sciences, Gonabad, Iran \\ 2Department of Environmental Health Engineering, School of Public Health, Sabzevar University of Medical Sciences, Sabzevar, Iran \\ ${ }^{3}$ Department of Engineering, Islamic Azad University-Kashmar Branch, Kashmar, Iran \\ ${ }^{4}$ Social Determinants of Health research center, Mashhad University of Medical Sciences, Mashhad, Iran \\ ${ }^{5}$ Department of Environmental Health Engineering, School of Health, Mashhad University of Medical Sciences, Mashhad, Iran \\ ${ }^{6}$ Institute of General and Inorganic Chemistry of National Academy of Sciences of Belarus, st. Surganova 9/1, 220072 Minsk, Belarus \\ ${ }^{7}$ National Centre for Metallurgical Research, CSIC, Avda. Gregorio del Amo 8, Madrid, 28040, Spain \\ ${ }^{8}$ Department of Chemistry, College of Science, Imam Abdulrahman Bin Faisal University, P.O. Box 1982, Dammam 31441, Saudi Arabia \\ Received: 27/12/2017, Accepted: 17/09/2018, Available online: 26/09/2018 \\ *to whom all correspondence should be addressed: e-mail: shamsmh@mums.ac.ir
}

https://doi.org/10.30955/gnj.002562

\section{Abstract}

A facile strategy toward modification of aluminium filings $(A F)$, a waste material from aluminium manufacturing industry, into a highly efficient adsorbent was examined. AF was simply treated with thermal modification to form a cheap adsorbent for Phosphorus (P) removal from aqueous solutions. The results showed that increasing the calcination temperature from 500 to $900^{\circ} \mathrm{C}$ improved the $P$ removal. $P$ adsorption occurred quite fast and $70 \%$ of $P$ removal observed in 15 minutes. Adsorption efficiency was increased by increasing $\mathrm{pH}$, decreasing $\mathrm{P}$ initial concentration as well. The presence of coexisting anions, except $\mathrm{HCO}_{3}{ }^{-}$, showed a negligible effect on $\mathrm{P}$ adsorption by AF. Thermodynamic studies revealed that $\mathrm{P}$ adsorption onto AF was endothermic in nature. Kinetic modelling demonstrated that the adsorption rate was controlled by the chemisorption. The process also fitted well with the Langmuir isotherm model, indicating that the process proceeds via monolayer coverage with $49.97 \mathrm{mg} \mathrm{g}^{-1}$ maximum monolayer capacity. Overall, in addition to beneficial environmental and economic aspects, the results demonstrated excellent adsorption characteristics which make thermally treated AF a promising adsorbent material for phosphorus removal from polluted streams.

Keywords: Low cost adsorbent, Aluminium filings, Phosphorus removal, Kinetic, Isotherm

\section{Introduction}

Phosphorus (P) as an essential macronutrient plays important role in the growth of photosynthetic algae and cyanobacteria (Oguz, 2005). Pollution in aquatic environments is generally associated with industrial and agricultural activities and domestic sewage discharges (Chen et al., 2010). Previous studies have shown that the human activities have tripled the environmental background of bio-available $P$ (Liu et al., 2012). This phenomenon is of the etiological causes of taste, odour, turbidity, water treatment problems, interference with recreational activities and depletion and changes in aquatic biodiversity (Smith, 2003). Therefore, P removal from wastewaters is a key factor in preventing eutrophication of water bodies, which can be achieved by different techniques including chemical precipitation, crystallization, adsorption and biological treatment (Nittami et al., 2011, Seviour et al., 2003). Although, at the present time, precipitation using metallic salts, particularly alum, is a common approach, high chemical consumption and sludge production, high space requirement, and difficulty in design and operation are the main drawbacks of precipitation (Jellali et al., 2010). Biological methods, on the other hand, tend to be sensitive and are subjected to many fluctuations and sometimes required to effluent filtration and/or chemical dosing, making operating problems and difficulties to meet the discharge criteria (de Haas and DW 2000).

Considering the economic and environmental aspects, adsorption is an interesting approach for removing $\mathrm{P}$ from municipal and industrial wastewaters. In attempt to develop the available, efficient, cost effective and environmentally benign adsorbents, several $\mathrm{P}$ adsorbents have been proposed by researchers. Many of these adsorbents are waste or cheap materials, such as fly ash (Oguz, 2005, Ugurlu and Salman, 1998), gravel and industrial-waste substrata (Mann and Bavor, 1993), phosphate mine wastes (Jellali et al., 2010, Jellali et al., 2011), blast furnace slag (Johansson, 1999, Gong et al., 2009), iron humate (Janoš et al., 2011), soils (Liang et al., 2010), and limestone (Mateus et al., 2012). Aluminium compounds have been extensively used for water and wastewater treatment purposes. Activated aluminium 
oxide (Genz et al., 2004), activated alumina (Narkis and Meiri, 1981), aluminium coated materials (Arias et al., 2006, Ayoub et al., 2001, Sansalone and Ma, 2009), and novel composite coagulants (Tzoupanos and Zouboulis, 2010) all are examples of aluminium based compounds. Aluminium compounds have also been proposed as a cost-effective lake restoration material (Reitzel et al., 2006, de Vicente et al., 2008, Reitzel et al., 2003, Reitzel et al., 2005). In addition, some studies have shown that the addition of aluminium compounds into anaerobic digestion basin can be effective in $\mathrm{P}$ removal and odour control (Novak and Park, 2010).

Aluminium filing is an available and low cost by-product of aluminium manufacturing industry. This envisages its economic advantage for being used in real adsorption systems. Due to its physical-chemical properties, AF is a viable material for use in continuous flow reactors (as filter media) or batch sorption units. The present study aims to investigate the possibility of using Aluminium fillings as a sorbent material for removal of $P$ from aqueous solutions. Aluminium fillings were thermally treated at different temperatures and, after temperature optimization; the adsorption experiments were carefully conducted to explore the effect of physiochemical parameters on the adsorption process. Kinetics and equilibrium studies were also performed, along with a thermodynamic evaluation, to reveal the properties of the removal process.

\section{Materials and methods}

The Aluminium Filings (AF) used in the present study was kindly provided by a local aluminium manufacturing company (Iranian Aluminium Company (IRALCO)). The asreceived $A F$ was washed several times with deionized water, dried at $60^{\circ} \mathrm{C}$, and then activated thermally by heating in an oven at different temperatures $(500,700$, $900^{\circ} \mathrm{C}$ ). Table 1 shows the elemental composition of $\mathrm{AF}$ obtained from the Iranian Aluminium Company (IRALCO).

Table 1. Elemental composition of AF (declared by the IRALCO company)

\begin{tabular}{cccc}
\hline Element & Composition \% & Element & Composition \% \\
\hline $\mathrm{Al}$ & 99.7 & $\mathrm{Ga}$ & 0.03 \\
\hline $\mathrm{Si}$ & 0.1 & $\mathrm{Cu}$ & 0.01 \\
\hline $\mathrm{Fe}$ & 0.2 & $\mathrm{Mg}$ & 0.02 \\
\hline $\mathrm{Zn}$ & 0.03 & Others & 0.03 \\
\hline
\end{tabular}

The characterization of the waste samples was performed by X-ray diffraction (XRD, in a diffractometer D8-Advance Bruker using CuK $\alpha$ radiation $(\lambda=0.15406 \mathrm{~nm})$ ) and field emission scanning electron microscopy (FESEM, in a VEGA//TESCAN microscope).

A stock solution of $\mathrm{P}\left(1000 \mathrm{mg} \mathrm{L}^{-1}\right)$ was prepared from dissolution of $\mathrm{K}_{2} \mathrm{HPO}_{4}$ in distilled water and then diluted to the desired concentration prior to use. After adding a desired amount of thermally treated aluminium filing (TT/AF), the suspensions were agitated using a rotary shaker at $250 \mathrm{rpm}$ for a specified time. Samples then were filtered through Whatman No. 42 filter paper, and residual $\mathrm{P}$ in the aqueous solutions was determined by the stannous chloride method using a UNICO UV-2100 spectrophotometer. All the adsorption experiments were carried out at room temperature $\left(23 \pm 2^{\circ} \mathrm{C}\right)$ without controlling $\mathrm{pH}$.

$P$ adsorption was studied as a function of adsorbent dose (0.2-20.0 $\left.\mathrm{g} \mathrm{L}^{-1}\right)$, contact time (15-600 min), AF activation temperature $\left(500-900^{\circ} \mathrm{C}\right), \mathrm{pH}(2-12)$, initial $\mathrm{P}$ concentration (20-100 mg L $\left.{ }^{-1}\right)$, coexisting anions $\left(\mathrm{HCO}_{3}{ }^{-}\right.$, $\mathrm{CO}_{3}{ }^{2-}, \mathrm{SO}_{4}{ }^{2-}, \mathrm{Cl}^{-}, \mathrm{NO}_{3}{ }^{-}$) and adsorption temperature (20$70^{\circ} \mathrm{C}$ ). The removal efficiency (\%) of the adsorbents at any time was calculated as follows:

$R E \%=\frac{\left(C_{0}-C_{t}\right)}{C_{0}} \times 100$

where $\mathrm{C}_{0}\left(\mathrm{mg} \mathrm{L}^{-1}\right)$ is the initial concentration of $\mathrm{P}, \mathrm{C}_{t}\left(\mathrm{mg} \mathrm{L}^{-1}\right)$ is the $P$ concentration at any time, $V(L)$ is the volume of $P$ solution, and $\mathrm{m}(\mathrm{g})$ is the TT/AFx mass dosage.

Equilibrium studies were performed by conducting $P$ adsorption as a function of initial $P$ concentration at constant temperature. Data then were analysed, using non-linear forms of Langmuir, Freundlich, and sips isotherms, in order to find the best fitted isothermal model. Kinetic studies were also executed by tracking the $\mathrm{P}$ adsorbed onto AF at different times, and modelling the experimental data with different kinetic models.

Goodness-of-fit evaluation of experimental data with the models was checked by non-linear regression analysis, and chi-square test, using the following equations (Tran et al., 2017a, Hosseini-Bandegharaei et al., 2016a).

$R^{2}=1-\frac{\sum\left(q_{e, \text { exp }}-q_{e, \text { cal }}\right)^{2}}{\sum\left(q_{e, \text { exp }}-q_{e, \text { mean }}\right)^{2}}$

$\chi^{2}=\sum_{i=1}^{N}\left(\frac{\left(q_{e, \text { exp }}-q_{e, c a l}\right)^{2}}{q_{e, c a l}}\right)$

where $q_{\exp }$ is the experimental value of the adsorption capacity $\left(\mathrm{mg} \mathrm{g}^{-1}\right)$, $\mathrm{q}_{\mathrm{cal}}$ is the calculated of the adsorption capacity from model $\left(\mathrm{mg} \mathrm{g}^{-1}\right)$ after using the Solver add-in in Excel software, $\mathbf{q}_{\text {mean }}$ is the average of the experimental adsorption capacity $\left(\mathrm{mg} \mathrm{g}^{-1}\right)$, and $\mathrm{N}$ is the number of measurements made.

\section{Results and discussion}

\subsection{Optimization of calcination temperature}

The batch sorption experiments were carried out using thermally treated AFs at 500, 700 and $900^{\circ} \mathrm{C}$ for 4 hours. As presented in Fig. 1, a substantial $P$ removal was achieved when AF samples were calcined at higher temperatures.

Since the thermally treated sample at $900^{\circ} \mathrm{C}$ (TT/AF900) showed the highest removal efficiency of $P$, further adsorption studies were focused only on this thermally treated adsorbent.

\subsection{Characterization studies}

Based on the temperature used, heating up aluminium particles in air atmosphere leads to formation of 
crystalline or amorphous alumina phases on the surface of particles (Rufino et al., 2007). In order to study the type of aluminium oxide formed after thermal treating of aluminium filings at $900^{\circ} \mathrm{C}$, FESEM micrograph were taken from the surface of TT/AF900 and XRD pattern of this sample was recorded (Fig. 2).

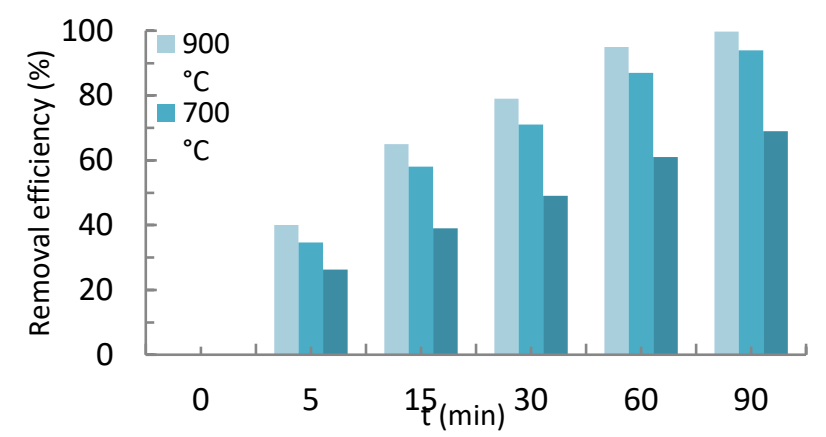

Figure 1. Effect of AF activation temperature on $P$ removal. Adsorbent dose: $5 \mathrm{~g} \mathrm{~L}^{-1}$, P initial concentration: $10 \mathrm{mg} \mathrm{L}^{-1}$

The obtained XRD pattern shows that, after thermal treating at $900^{\circ} \mathrm{C}$ for $4 \mathrm{~h}$, the waste aluminium fillings are coated with different type of aluminium oxides, especially $\gamma$ and $\alpha$ types. Furthermore, from the FESEM micrographs, one can observe both $\alpha$ - and $\gamma$-alumina crystalline structures along with amorphous aluminium oxide.

\subsection{Effect of adsorbent dose}

$P$ solutions were mixed with different AF masses and, the plot of $\mathrm{P}$ removal percentage against adsorbent dose was presented in Fig. 3. As can be seen, the effect of dose is dependent on the spending contact time. For example, at the contact time of $1.5 \mathrm{~h}$, increasing AF dose from 3 to 10 $\mathrm{g} \mathrm{L}^{-1}$ enhanced $\mathrm{P}$ removal from 85 to $100 \%$. This might be demonstrated eventually by the increase of accessible adsorption sites for $\mathrm{P}$ removal with increase in adsorbent dose. In addition, Fig. 3 revealed that, for all the adsorbent doses used, the $\mathrm{P}$ adsorption onto AF was occurred quite rapid and most of the $P$ was removed within the first minutes of agitation time. This behaviour can be attributed to the quick utilization of the most readily available adsorbing sites of the adsorbent, which is similar to the results published by Cheng et al. (2017) who studied $\mathrm{P}$ removal by $\mathrm{NaCl}$-modified zeolite. Notably, using contact time of $1.5 \mathrm{~h}$, the adsorbent dose of $5 \mathrm{~g} \mathrm{~L}^{-1}$ also is capable to bring up almost the complete removal efficiency (99.8\%). Therefore, in the conditions used in this study, $5 \mathrm{~g} \mathrm{~L}^{-1}$ is the optimum dose of adsorbent. Also, it should be mentioned that the high rapidness of adsorption process within the first minutes of contact time has a great economic importance in scaling up the adsorption system to a real treatment unit.

\subsection{Effect of $\mathrm{pH}$}

To study the effect of $\mathrm{pH}$, the acidity of solutions was adjusted with $0.1 \mathrm{M}$ solution $\mathrm{KOH}$ or $\mathrm{HNO}_{3}$ and the percentage removal of $\mathrm{P}$ was determined after $30 \mathrm{~min}$ of agitation time. As depicted in Fig. 4, P percentage removal increased with $\mathrm{pH}$ increasing from 4 to 10 and, then, decreased with increasing $\mathrm{pH}$ to higher values. The decline

in removal efficiency upon $\mathrm{pH} 10$ is ascribed to the competition between $\mathrm{OH}^{-}$ions and negatively charged $\mathrm{P}$ for the available adsorbent sites. In addition, a sudden decrease in $\mathrm{P}$ adsorption occurred when $\mathrm{pH}$ of the solution fixed below 4, which could be related to the predominant presence of $P$ as acidic species which cannot make a suitable attractive interaction with a positively charged adsorbent.
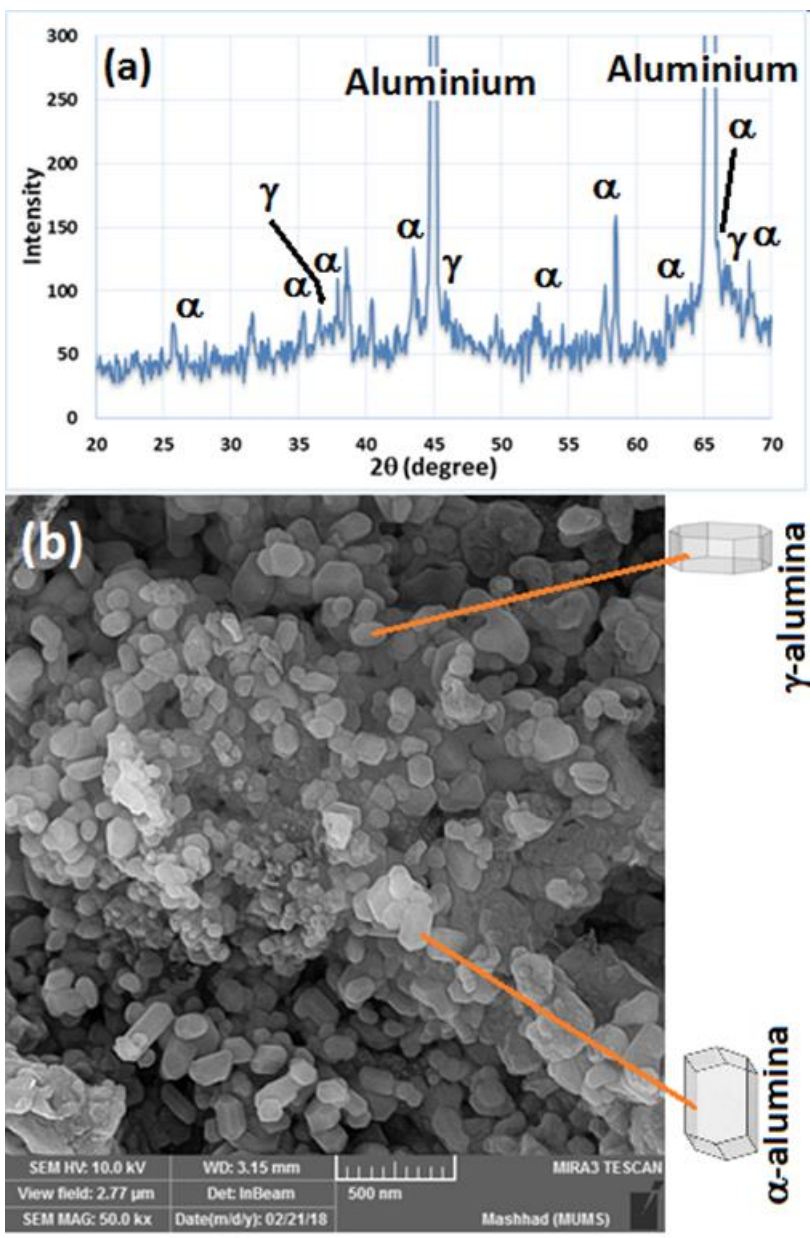

Figure 2. XRD pattern (a) and FESEM micrograph (b) of TT/AF 900 sample

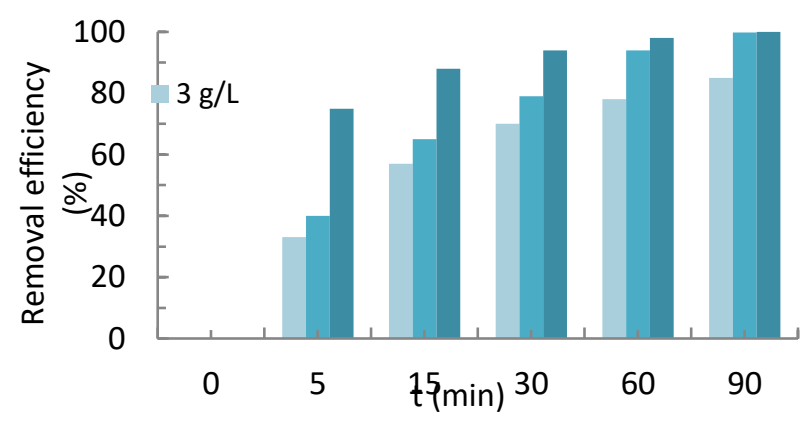

Figure 3. Effect of $T \mathrm{~T} / \mathrm{AF}_{900}$ dose on $\mathrm{P}$ removal. $\mathrm{P}$ initial concentration: $10 \mathrm{mg} \mathrm{L}^{-1}$ 


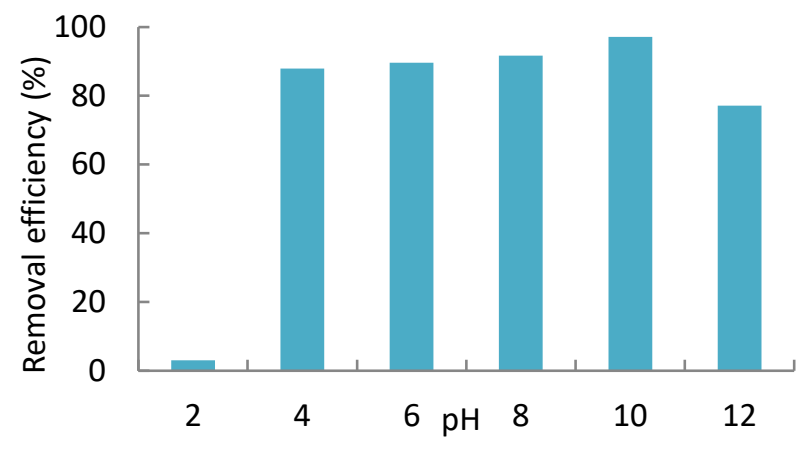

Figure 4. Effect of $\mathrm{pH}$ on $\mathrm{P}$ adsorption. $\mathrm{P}$ initial concentration: 10 $\mathrm{mg} \mathrm{L}^{-1}$, adsorbent dose: $5 \mathrm{~g} \mathrm{~L}^{-1}$, agitation: $100 \mathrm{~min}$

Since the point of zero charge is of high importance in describing the interaction between adsorbent and adsorbate, $\mathrm{pH}_{\mathrm{Pzc}}$ was estimated by utilizing the drift method. The value of $\mathrm{pH}_{\mathrm{Pzc}}$ for TT/AF900 was 9.6 which almost shows a good agreement with the previously reported values, e.g. 9.6 (Yopps and Fuerstenau, 1964) and 9.5 (Reyes Bahena et al., 2002), for $\alpha$-alumina. It can be concluded from the obtained results that there are an attractive forces between negatively charged $p$ and TT/AF9oo at the pHs lower than 9.6, and after $\mathrm{pH} 10$ repulsive electrostatic forces vanquish the adsorption affinity of the adsorbent towards adsorbate.

From the speciation diagram of phosphate in the aqueous solutions (Clifford, 1961), it is obvious that, in the $\mathrm{pH}$ range 4-10, anionic phosphate may be present in the forms of $\mathrm{H}_{2} \mathrm{PO}^{-}, \mathrm{HPO}_{4}{ }^{2-}$ and $\mathrm{PO}_{4}{ }^{3-}$, with different percentages. Therefore, the results obtained from the study of effect of pH (Fig. 4) show that the adsorbent has a good affinity towards all anionic forms of phosphorus. However, higher adsorption ability of the adsorbent at $\mathrm{pH}$ 10 is an evidence for its higher affinity to triple negatively charged anion $\left(\mathrm{PO}_{4}{ }^{3-}\right)$ which is the predominant species in such condition. The concentration of $\mathrm{H}_{3} \mathrm{PO}_{4}$ species is higher for $\mathrm{pHs}$ below 4 which is an extra reason for the low removal efficiency at low pHs, besides the positively charged surface of adsorbent at high acidities which prohibits from the adsorption of a negatively charged adsorbate ( $\mathrm{PO}_{4}{ }^{3-}$ anion).

\subsection{Effect of initial $P$ concentration}

Since the initial concentration of adsorbate affects on the adsorption efficiency of adsorbent towards adsorbate (Alahabadi et al., 2017), the impact of initial P concentration on adsorption was investigated in the range of $20-100 \mathrm{mg} \mathrm{L}^{-1}$. As presented in Fig. 5, the removal efficiency decreased with increasing $P$ concentration.

The results indicated that, the initial $P$ concentration is considered as the motivating force for vanquishing the mass transfer limitation among the adsorbent and the aqueous solution. Nevertheless, at higher concentration the available active sites became fewer compared to the number of phosphorus moles and thus decreasing in percentage removal.

\subsection{Effect of interfering anions}

$\mathrm{P}$ adsorption in the presence of competing ions $\left(\mathrm{HCO}_{3}{ }^{-}\right.$, $\mathrm{CO}_{3}{ }^{2-}, \mathrm{Cl}^{-}, \mathrm{NO}_{3}{ }^{-}$, and $\mathrm{SO}_{4}{ }^{2-}$ ) with the concentrations of 200 and $400 \mathrm{mg} \mathrm{L}^{-1}$ was studied, and the obtained results were summarized in Fig. 6. Since the $\mathrm{pH}$ of the solutions was not controlled during the experiments, after adding the potassium salts of interfering above ions, the final $\mathrm{pH}$ value of the solutions was $6.77,6.83,6.88,9.15$ and 8.54 , respectively. As it is evident in Fig. $6(\mathrm{a}), \mathrm{HCO}_{3}{ }^{-}$interfering ion has the highest influence on $\mathrm{P}$ removal by AF. Also, according to Fig. 6(b), and except in the case of $\mathrm{HCO}_{3}{ }^{-}$, increasing the concentration of interfering ions from 200 to $400 \mathrm{mg} \mathrm{L}^{-1}$ has a negligible influence on the $P$ adsorption by AF.

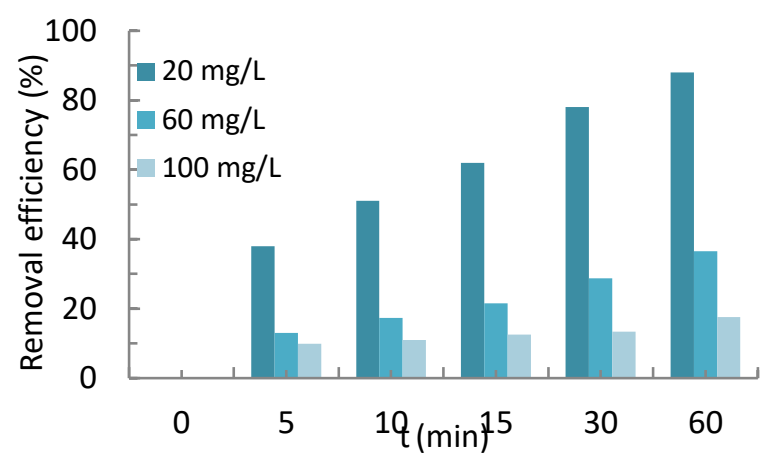

Figure 5. Effect of initial $\mathrm{P}$ concentration on $\mathrm{P}$ adsorption onto $\mathrm{TT} / \mathrm{AF}_{900}$. Adsorbent dose: $5 \mathrm{~g} \mathrm{~L}^{-1}$

\subsection{Adsorption temperature}

To inspect the effect of temperature on the removal process, studies were performed at different temperatures $\left(30-70^{\circ} \mathrm{C}\right)$ with $10 \mathrm{mg} \mathrm{L} \mathrm{L}^{-1}$ of $\mathrm{P}$ initial concentration. As presented in Fig. 7, the results disclosed that the percentage removal of $P$ increased as the temperature increased, indicating the endothermic nature of the adsorption process. The adsorption rate was improved gradually after changing the temperature from $30^{\circ} \mathrm{C}$ to $70^{\circ} \mathrm{C}$. This approach can be assigned to the following factors: (a) increasing the temperature of solution will certainly affect the movement of ions, (b) enhancing the swelling effect within the internal structure of the adsorbent material, (c) increasing the penetration of ions within liquid/solid interface (Alakhras et al., 2018).

\subsection{Kinetic study}

Kinetic study is important in determining the ratecontrolling mechanism of the adsorption. Also, from an industrial point of view, study on the kinetic aspects of adsorption process is necessary for system design. Therefore, kinetic experiments were conducted with adding fixed mass of TT/AF9oo to the solutions containing 10-100 $\mathrm{mg} \mathrm{L}^{-1}$ of $\mathrm{P}$, the amount of $\mathrm{P}$ adsorbed on TT/AF900 at any time $\left(q_{\mathrm{t}}, \mathrm{mg} \mathrm{g}^{-1}\right)$ was calculated as follows:

$q_{t}=\frac{\left(C_{0}-C_{t}\right)}{m} \times V$ 
where $\mathrm{C}_{0}\left(\mathrm{mg} \mathrm{L}^{-1}\right)$ is the initial concentration of $\mathrm{P}, \mathrm{C}_{\mathrm{t}}\left(\mathrm{mg} \mathrm{L}^{-1}\right)$ is the $P$ concentration at contact time $t, V(L)$ is the
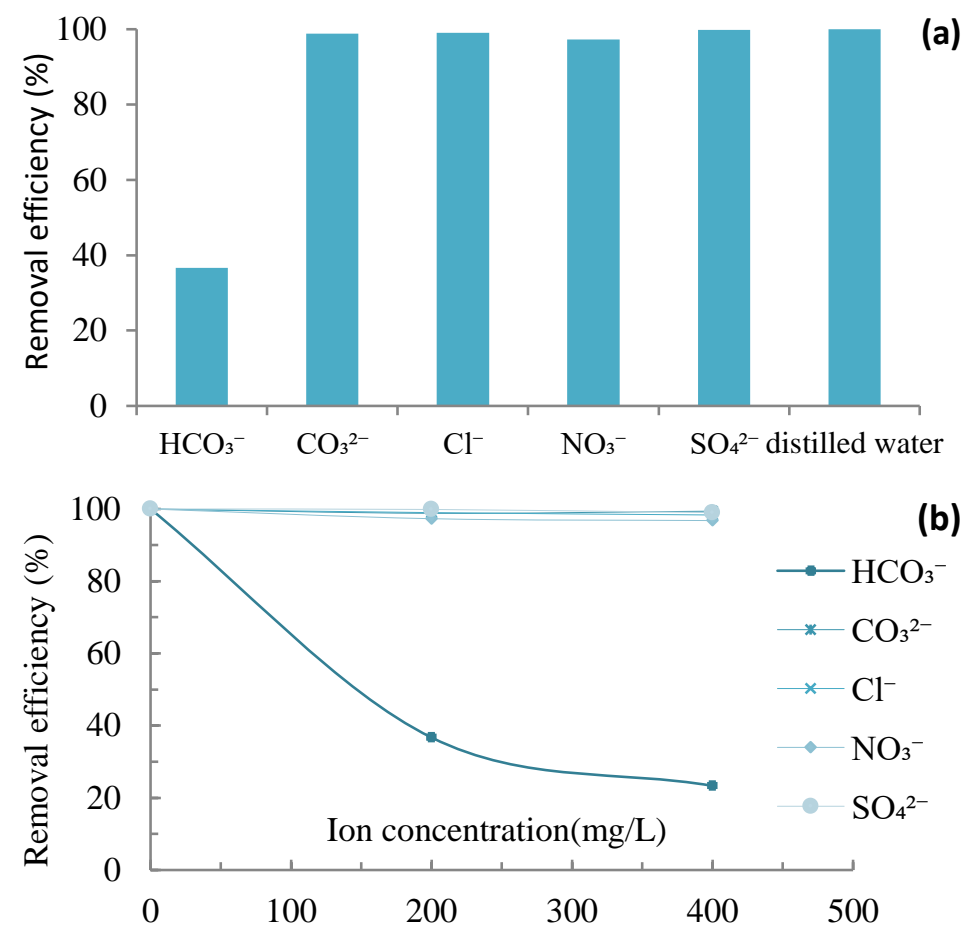

Figure 6. Effects of competing anions (a) and their concentrations on the efficiency of removal of $p$ by TT/AF 900 (b). P initial concentration: $10 \mathrm{mg} \mathrm{L}^{-1}$, agitation time: $100 \mathrm{~min}$, and adsorbent dose: $5 \mathrm{~g} \mathrm{~L}^{-1}$

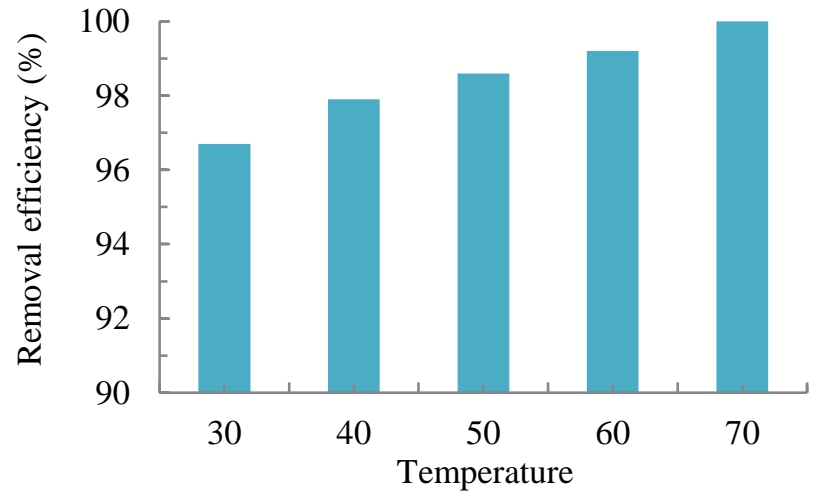

Figure 7. Effect of temperature on $\mathrm{P}$ adsorption. $\mathrm{P}$ initial concentration: $10 \mathrm{mg} \mathrm{L}^{-1}$, agitation time: $30 \mathrm{~min}$, and adsorbent dose: $5 \mathrm{~g} \mathrm{~L}^{-1}$

Then, the kinetic parameters of adsorption process were evaluated by fitting the experimental data with non-linear form of the following kinetic models:

Pseudo-first order model (Yuh-Shan, 2004):

$q_{t}=q_{e}\left(1-e^{k_{1} t}\right)$

Pseudo-second order model (Ho, 2006):

$q_{t}=\frac{q^{2} k_{2} t}{1+k_{2} q_{e} t}$ where $q_{e}$ and $q_{t}$ are the amounts of $\mathrm{P}$ adsorbed per gram of TT/AF 900 at equilibrium and at time $t$, respectively, $\mathrm{K}_{1}$ is the rate constant of pseudo first-order adsorption $\left(\mathrm{min}^{-1}\right)$, and $\mathrm{k}_{2}$ is the rate constant of pseudo second-order adsorption ( $\mathrm{g} \mathrm{mg}^{-1} \mathrm{~min}^{-1}$ ).

Fig 8(a) depicted the non-linear fit of adsorption process with the aforementioned kinetic models for $\mathrm{P}$ adsorption by the $T T / A_{900}$, and the kinetic parameters obtained are reported in Table 2. The results exhibited that, based on the higher values of $\mathrm{R}^{2}$, the lower values of $\chi^{2}$, and closeness of values of $q_{\mathrm{e}, \text { cal }}$ and $q_{\mathrm{e} \text { exp }}$, the pseudo-second order kinetic model is the best prototype for describing $P$ adsorption onto the TT/AF900. These findings indicate that the interaction between the adsorbate and adsorbent is the rate controlling step in P adsorption onto TT/AF900.

To gain insight on the effect of pore diffusion on the possibility of contribution of intra-particle mechanism in the adsorption mechanism, the kinetic studies were extended by fitting the experimental data with an intraparticle diffusion kinetic model originally proposed by Weber-Morris equation (Weber and Morris, 1963):

$\mathrm{q}_{\mathrm{t}}=\mathrm{k}_{\mathrm{ip}} \mathrm{t}^{0.5}+\mathrm{C}$

Where $k_{i p}$ is the rate constant of intra-particle diffusion $\left(\mathrm{mg} \mathrm{g}^{-1} \min ^{-0.5}\right), q_{t}$ is the adsorption capacity of $\mathrm{P}$ at time $t$ $\left(\mathrm{mg} \mathrm{g}^{-1}\right)$, and the value of $C$ is the intercept. If the intraparticle diffusion is the rate controlling step, then a plot of $q_{t}$ vs. $\mathrm{t}^{0.5}$ will be a straight line which passes through the 
origin (Nosrati et al., 2017, Khamirchi et al., 2018). From the kinetic plots of intra-particle diffusion model (Fig. 8(b)), however, the straight lines of plots did not meet this criterion. Therefore, the results indicated that intraparticle diffusion is not the only rate-controlling step and this process might be organized by a chemical reaction as well. Such results seem to be rational because the studied adsorbent is not of a very high porosity.

Table 2. Parameters of pseudo-first order and pseudo-second order kinetic models for adsorption of $\mathrm{P}$ by TT/AF 900 at different initial concentrations

\begin{tabular}{|c|c|c|c|c|c|}
\hline \multirow{3}{*}{$\mathrm{C}_{0}\left(\mathrm{mg} \mathrm{L}^{-1}\right)$} & \multicolumn{5}{|c|}{ Models parameters } \\
\hline & \multicolumn{5}{|c|}{ Pseudo-first order model } \\
\hline & $k_{1}\left(\min ^{-1}\right)$ & $q_{e, \text { cal }}\left(\mathrm{mg} \mathrm{g}^{-1}\right)$ & $\mathbf{R}^{2}$ & $\chi^{2}$ & $q_{e, \exp }\left(m g^{-1}\right)$ \\
\hline 20 & $2.745 \mathrm{E}-02$ & 16.268 & 0.9939 & 0.106 & 17.031 \\
\hline 60 & $2.193 \mathrm{E}-02$ & 34.750 & 0.9984 & 0.241 & 38.121 \\
\hline \multirow[t]{3}{*}{100} & $2.365 \mathrm{E}-02$ & 44.892 & 0.9987 & 0.308 & 45.208 \\
\hline & \multicolumn{5}{|c|}{ Pseudo-second order model } \\
\hline & $k_{2}\left(g g^{-1} \min ^{-1}\right)$ & $q_{e, \text { cal }}\left(\mathrm{mg} \mathrm{g}^{-1}\right)$ & $\mathbf{R}^{\mathbf{2}}$ & $\chi^{2}$ & $q_{e, \exp }\left(\mathrm{mg} \mathrm{g}^{-1}\right)$ \\
\hline 20 & $1.484 \mathrm{E}-03$ & 19.124 & 0.9971 & 0.088 & 17.031 \\
\hline 60 & 5.007E-04 & 43.666 & 0.9997 & 0.033 & 38.121 \\
\hline 100 & 4.334E-04 & 55.811 & 0.9993 & 0.115 & 45.208 \\
\hline
\end{tabular}
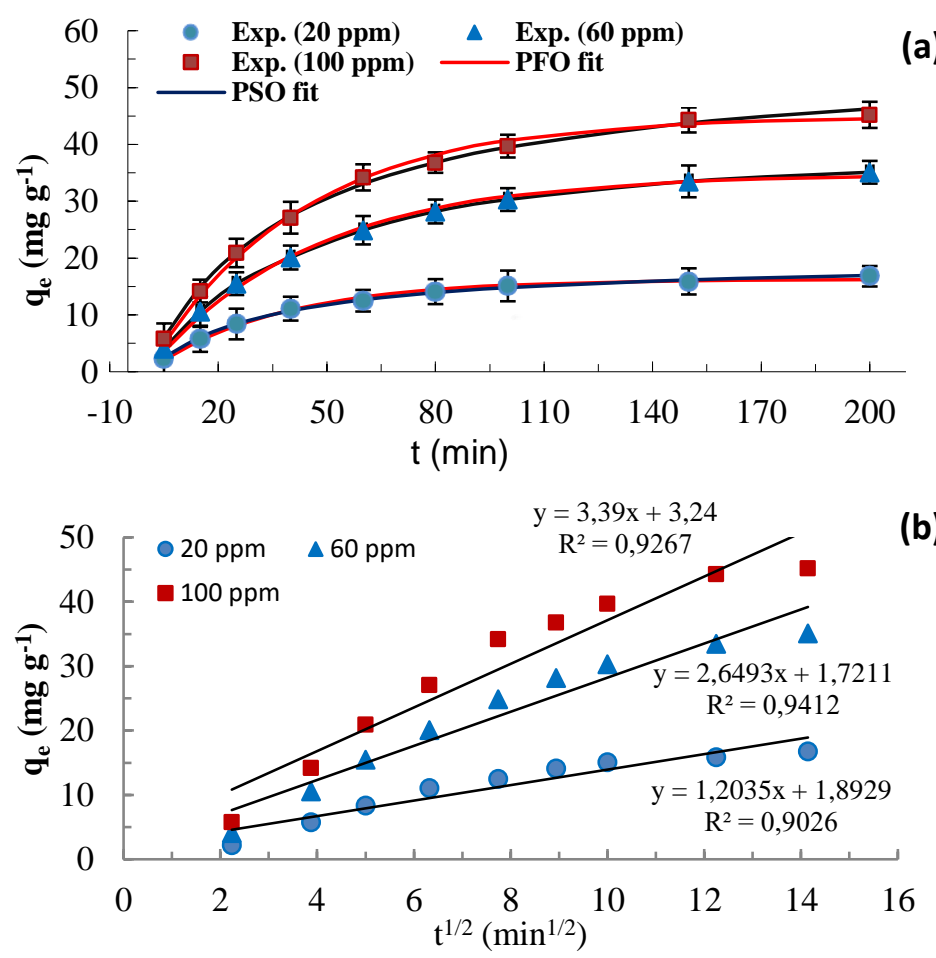

(b)

Figure 8. Fitting pseudo-first order, pseudo-seconder order (a) and intra-particle diffusion (b) kinetic models with experimental data of $\mathrm{P}$ adsorption by $\mathrm{TT} / \mathrm{AF}_{900}$

\subsection{Equilibrium study}

Equilibrium study is a basic requirement for the design of real adsorption systems, since it provides necessary information about the capacity of the adsorbent towards the interested pollutant.

The concentration of $P$ remained in the solution at equilibrium was employed to calculate the amount of $p$ adsorbed on TT/AF90o at equilibrium $\left(q_{e}, \mathrm{mg} \mathrm{g}^{-1}\right.$ ), using the following relation:
$q_{e}=\frac{\left(C_{0}-C_{e}\right)}{m} \times V$

where $\mathrm{C}_{0}\left(\mathrm{mg} \mathrm{L}^{-1}\right)$ is the initial concentration of $\mathrm{P}, \mathrm{C}_{\mathrm{e}}$ $\left(\mathrm{mg} \mathrm{L}^{-1}\right)$ is the $P$ concentration at equilibrium, $V(L)$ is the volume of $\mathrm{P}$ solution, and $\mathrm{m}(\mathrm{g})$ is the TT/AF900 mass.

The isothermal adsorption data were analysed to find the best fitting isotherm using two commonly used twoparameter models, Langmuir and Freundlich, and one three-parameter model, Langmuir-Freundlich (Sips) model, which can be given as the following equations: 
Langmuir model:

$q_{e}=\frac{q_{\max } b c_{e}}{1+b c_{e}}$

Freundlich model:

$\mathrm{q}_{\mathrm{e}}=\mathrm{k}_{\mathrm{F}} \mathrm{C}_{\mathrm{e}}^{1 / \mathrm{n}}$

Sips model:

$\mathrm{q}_{\mathrm{e}}=\frac{\mathrm{q}_{\max }\left(\mathrm{K}_{\mathrm{s}} \mathrm{C}_{\mathrm{e}}\right)^{1 / \mathrm{n}_{\mathrm{s}}}}{1+\left(\mathrm{K}_{\mathrm{s}} \mathrm{C}_{\mathrm{e}}\right)^{1 / \mathrm{n}_{\mathrm{s}}}}$

In the above equations, $\mathrm{C}_{e}$ is the equilibrium concentration of $P$ in aqueous phase $\left(\mathrm{mg} \mathrm{L}^{-1}\right), q_{e}$ is the adsorption capacity of TT/AF900 at the equilibrium $\left(\mathrm{mg} \mathrm{g}^{-1}\right)$, $\mathrm{b}$ is Langmuir constant related to the affinity of adsorption sites for $\mathrm{P}\left(\mathrm{L} \mathrm{mg}^{-1}\right), \mathrm{q}_{\max }$ is theoretical maximum sorption capacity calculated from isotherm model $\left(\mathrm{mg} \mathrm{g}^{-1}\right), \mathrm{K}_{\mathrm{f}}$ is Freundlich constant which is roughly an indicator for the sorption capacity $\left(\mathrm{mg}^{1-(1 / n)} \mathrm{L}^{1 / \mathrm{n}} \mathrm{g}^{-1}\right), \mathrm{n}$ is Freundlich constant indicative of the sorption intensy and heterogeneity, $\mathrm{K}_{\mathrm{s}}$ is the Sips equilibrium constant $\left(\mathrm{L} \mathrm{g}^{-1}\right)$, and $\mathrm{n}_{\mathrm{s}}$ is Sips constant which characterize the adsorption heterogeneity.

The Langmuir isotherm is based on the assumption that adsorption occurs via monolayer coverage. Equivalency and independency of adsorption sites are two other assumptions considered in a developed Langmuir model (Sohn and Kim, 2005).

The non-linearized form of both two-parameter models and the three-parameter model were fitted with experimental data (Fig. 9), and the calculated parameters for all the studied models were reported in Table 3 . The results illustrated that, based on $\mathrm{R}^{2}$ and $\chi^{2}$. values obtained, the Sips model provided a good fit with experimental data. However its exponent is close to unity ( $\left.n_{s}=0.986\right)$, which means that the process is best described by the Langmuir isotherm, and the adsorption of $P$ onto TTAF 900 is of homogeneity nature rather than heterogeneity. In consonance with this conclusion, amongst the two-parameter models, based on the higher value of correlation coefficient $\left(R^{2}\right)$ and the lower value of statistical index $\left(\chi^{2}.\right)$, the Langmuir model displayed the best fit with experimental data. The above resus indicated that the adsorption process of $\mathrm{P}$ onto TT/AF900 is homogenous and proceeded via monolayer adsorption, with a theoretical maximum monolayer adsorption capacity of $49.97 \mathrm{mg} \mathrm{g}^{-1}$.

In a study reported by Babatunde et al. which was focused on the potential evaluation of aluminium based residual as phosphate-removing substrate in constructed wetland, $q_{\max }$ of $31.9 \mathrm{mg} \mathrm{g}^{-1}$ was achieved (Babatundet al., 2009). Babatunde et al. found that the adsorption capacity of dewatered aluminium-coagulated water treatment residual for $\mathrm{P}$ removal was a function of $\mathrm{pH}$ and ranged from 4.52 to $1.74 \mathrm{mg} \mathrm{g}^{-1}$ at $\mathrm{pH} 4$ and 9, respectively (Babatunde et al., 2008). Applicability of freshly dewatered aluminium salt-based sludge as a filter material to adsorb $\mathrm{P}$ was proved in a previous study conducted by Razali (Razali et al., 2007). Overall, the result obtained in the equilibrium studies revealed that, comparing with other studies which have used waste aluminium material, thermally treated aluminium filings at $900^{\circ} \mathrm{C}$ are showing high potential as a competent material to remove $P$ from polluted aqueous solutions.

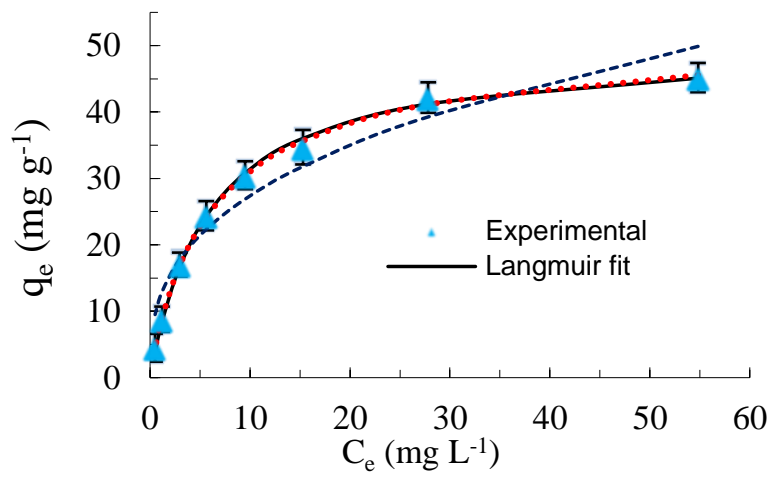

Figure 9. Fitting the non-linear forms of different isotherm models with experimental data of $\mathrm{P}$ adsorption by $\mathrm{TT} / \mathrm{AF}_{900}$

Table 3. Non-linear isotherm parameters of different models for adsorption of $\mathrm{P}$ by $\mathrm{TT}_{\mathrm{A}} / \mathrm{AF}_{900}$ at ambient temperature

\begin{tabular}{ccc}
\hline & Unit & Amount \\
\hline Langmuir model & & \\
\hline $\mathrm{q}_{\max }$ & $\mathrm{mg} \mathrm{g}^{-1}$ & 49.965 \\
\hline $\mathrm{B}$ & $\mathrm{L} \mathrm{mg}^{-1}$ & 0.169 \\
\hline $\mathrm{R}^{2}$ & - & 0.9979 \\
\hline$\chi^{2}$ & - & 0.196 \\
\hline Freundlich model & & \\
\hline $\mathrm{K}_{\mathrm{F}}$ & $\left(\mathrm{mg} \mathrm{g}^{-1}\right) /(\mathrm{mg}$ & 12.137 \\
\hline $\mathrm{N}$ & - & 2.833 \\
\hline $\mathrm{R}^{2}$ & - & 0.9400 \\
\hline$\chi^{2}$ & - & 5.590 \\
\hline Sips model & & \\
\hline $\mathrm{q}_{\max }$ & $\mathrm{mg} \mathrm{g}^{-1}$ & 51.955 \\
\hline $\mathrm{n}_{\mathrm{S}}$ & & 0.986 \\
\hline $\mathrm{K}_{\mathrm{S}}$ & $\mathrm{L} \mathrm{mg}^{-1}$ & 0.177 \\
\hline $\mathrm{R}^{2}$ & - & 0.9986 \\
\hline$\chi^{2}$ & - & 0.063 \\
\hline
\end{tabular}

3.10. Evaluation of Gibbs free energy change during the adsorption process

Evaluation of energetic changes during the adsorption process is of great importance in studying adsorption processes (Hosseini-Bandegharaei et al., 2016a, HosseiniBandegharaei et al., 2016b). Therefore, to assess the 
feasibility and spontaneity of the adsorption process, the change in the Gibbs free energy $\left(\Delta \mathrm{G}, \mathrm{J} \mathrm{mol}^{-1}\right)$ during the adsorption process was valuated from the results of isotherms studies reported in the preceding section, using the following equation (Rahmani-Sani et al., 2017, Tran et al., 2017b):

$$
\Delta \mathrm{G}=-\mathrm{R} \operatorname{Tln}\left(55.5 \mathrm{~b}_{\mathrm{M}}\right)
$$

where the gas constant $\mathrm{R}$ is defined by $8.3145 \mathrm{~J} \mathrm{~mol}^{-1} \mathrm{~K}^{-1}$, $\mathrm{b}_{\mathrm{M}}\left(\mathrm{L} \mathrm{mol}^{-1}\right)$ is the Langmuir equilibrium constant, 55.5 is the number of moles of water per liter of solution, and $T$ $(\mathrm{K})$ is the temperature of the solution.

The $\Delta G$ value at ambient temperature (296 K) for the adsorption of $\mathrm{P}$ onto TT/AF900 was calculated to be -14.37 $\mathrm{kJ} \mathrm{mol}^{-1}$. The negative sign of the Gibbs free energy change value was confirmed that the adsorption process of $P$ onto the surface of TT/AF900 was feasible and spontaneous.

\section{Conclusion}

Considering the importance of efficient use of industrial waste by-products for other purposes, a new way was found for usage of aluminium filling, a waste by-product of aluminium manufacturing industries which indeed is a highly abundant, cheap, easily available material, in the industry of water and wastewater treatment. In this work, thermally treated aluminium filing (TT/AF) was used as an adsorbent for removal of $P$ from aqueous solutions. The results showed that $A F$ treated at $900^{\circ} \mathrm{C}$ (TT/AF900) has a considerable adsorption capacity and a fast adsorption towards $\mathrm{P}$ in aqueous solution. TT/AF900 was capable of adsorption of $\mathrm{P}$ in vast range of $\mathrm{pH}$ (4-10).

The adsorption isotherms revealed that the $\mathrm{P}$ adsorption onto the adsorbent fit well the Langmuir model and the process is homogenous. Further, the adsorption kinetics study indicated that the Pseudo-second order model is well appropriate to describe the entire adsorption process. Also evaluation of Gibbs free energy showed that the process is feasible and spontaneous. Overall, the present study confirmed the technical feasibility of usage of aluminium waste-filings as a potential adsorbent for the removal of $P$ from the polluted aqueous media. Also, since the adsorbent is simply produced via thermally treatment of aluminium waste-fillings, its application to real wastewater and water treatment plants is costeffective.

\section{Acknowledgements}

Thanks to research council of Gonabad University of Medical Science for its financial support.

\section{References}

Alahabadi, A., Hosseini-Bandegharaei, A., Moussavi, G., Amin, B., Rastegar, A., Karimi-Sani, H., Fattahi, M. and Miri, M. (2017) Comparing adsorption properties of $\mathrm{NH} 4 \mathrm{Cl}$-modified activated carbon towards chlortetracycline antibiotic with those of commercial activated carbon. Journal of Molecular Liquids, 232, 367-381.

Alakhras, F., Ouerfelli, N., Al-Mazaideh, G., Ababneh, T., AlAbbad, E. and Abouzeid, F. (2018) Optimal pseudo-average order kinetic model for correlating the removal of nickel ions by adsorption on nanobentonite. Arabian Journal for Science and Engineering, 1-10.

Arias, M., Da Silva-Carballal, J., Garcia-Rio, L., Mejuto, J. and Nunez, A. (2006) Retention of phosphorus by iron and aluminum-oxides-coated quartz particles. Journal of colloid and interface science, 295(1), 65-70.

Ayoub, G.M., Koopman, B. and Pandya, N. (2001) Iron and aluminum hydroxy (oxide) coated filter media for lowconcentration phosphorus removal. Water Environment Research, 73(4), 478-485.

Babatunde, A., Zhao, Y., Burke, A., Morris, M. and Hanrahan, J. (2009) Characterization of aluminium-based water treatment residual for potential phosphorus removal in engineered wetlands. Environmental Pollution, 157(10), 2830-2836.

Babatunde, A., Zhao, Y., Yang, Y. and Kearney, P. (2008) Reuse of dewatered aluminium-coagulated water treatment residual to immobilize phosphorus: Batch and column trials using a condensed phosphate. Chemical Engineering Journal, 136(23), 108-115.

Chen, X., Chen, X., Wan, X., Weng, B. and Huang, Q. (2010) Water hyacinth (Eichhornia crassipes) waste as an adsorbent for phosphorus removal from swine wastewater. Bioresource Technology, 101(23), 9025-9030.

Cheng, Q., Li, H., Xu, Y., Chen, S., Liao, Y., Deng, F. and Li, J. (2017) Study on the adsorption of nitrogen and phosphorus from biogas slurry by NaCl-modified zeolite. PloS One, 12(5), e0176109.

Clifford, A.F. (1961) Inorganic Chemistry of Qualitative Analysis, Prentice-Hall.

de Haas, G. and DW, W. (2000) The use of simultaneous chemical precipitation in modified activated sludge systems exhibiting biological excess phosphate removal-Part 1 : Literature review. Water Sa, 26(4), 439-452.

de Vicente, I., Huang, P., Andersen, F. $\varnothing$. and Jensen, H.S. (2008) Phosphate adsorption by fresh and aged aluminum hydroxide. Consequences for lake restoration. Environmental Science \& Technology, 42(17), 6650-6655.

Genz, A., Kornmüller, A. and Jekel, M. (2004) Advanced phosphorus removal from membrane filtrates by adsorption on activated aluminium oxide and granulated ferric hydroxide. Water Research, 38(16), 3523-3530.

Gong, G., Ye, S., Tian, Y., Wang, Q., Ni, J. and Chen, Y. (2009) Preparation of a new sorbent with hydrated lime and blast furnace slag for phosphorus removal from aqueous solution. Journal of Hazardous Materials, 166(2-3), 714-719.

Ho, Y.-S. (2006) Review of second-order models for adsorption systems. Journal of Hazardous Materials, 136(3), 681-689.

Hosseini-Bandegharaei, A., Allahabadi, A., Rahmani-Sani, A., Rastegar, A., Khamirchi, R., Mehrpouyan, M., Hekmat-Shoar, R. and Pajohankia, Z. (2016b) Thorium removal from weakly acidic solutions using titan yellow-impregnated XAD-7 resin beads: kinetics, equilibrium and thermodynamic studies. Journal of Radioanalytical and Nuclear Chemistry, 309(2), 761-776.

Hosseini-Bandegharaei, A., Khamirchi, R., Hekmat-Shoar, R., Rahmani-Sani, A., Rastegar, A., Pajohankia, Z. and Fattahi, E. (2016a) Sorption efficiency of three novel extractantimpregnated resins containing vesuvin towards $\mathrm{Pb}$ (II) ion: Effect of nitrate and amine functionalization of resin 
backbone. Colloids and Surfaces A: Physicochemical and Engineering Aspects, 504, 62-74.

Janoš, P., Kopecká, A. and Hejda, S. (2011) Utilization of waste humate product (iron humate) for the phosphorus removal from waters. Desalination, 265(1-3), 88-92.

Jellali, S., Wahab, M.A., Anane, M., Riahi, K. and Bousselmi, L. (2010) Phosphate mine wastes reuse for phosphorus removal from aqueous solutions under dynamic conditions. Journal of Hazardous Materials, 184(1-3), 226-233.

Jellali, S., Wahab, M.A., Hassine, R.B., Hamzaoui, A.H. and Bousselmi, L. (2011) Adsorption characteristics of phosphorus from aqueous solutions onto phosphate mine wastes. Chemical Engineering Journal, 169(1-3), 157-165.

Johansson, L. (1999) Blast furnace slag as phosphorus sorbentscolumn studies. Science of the Total Environment, 229(1-2), 89-97.

Khamirchi, R., Hosseini-Bandegharaei, A., Alahabadi, A., Sivamani, S., Rahmani-Sani, A., Shahryari, T., Anastopoulos, I., Miri, M. and Tran, H.N. (2018) Adsorption property of BrPADAP-impregnated multiwall carbon nanotubes towards uranium and its performance in the selective separation and determination of uranium in different environmental samples. Ecotoxicology and Environmental Safety, 150, 136143.

Liang, H., Liu, J., Wei, Y. and Guo, X. (2010) Evaluation of phosphorus removal from wastewater by soils in rural areas in China. Journal of Environmental Sciences, 22(1), 15-22.

Liu, C., Kroeze, C., Hoekstra, A.Y. and Gerbens-Leenes, W. (2012) Past and future trends in grey water footprints of anthropogenic nitrogen and phosphorus inputs to major world rivers. Ecological Indicators, 18, 42-49.

Mann, R. and Bavor, H. (1993) Phosphorus removal in constructed wetlands using gravel and industrial waste substrata. Water Science and Technology, 27(1), 107-113.

Mateus, D.M., Vaz, M.M. and Pinho, H.J. (2012) Fragmented limestone wastes as a constructed wetland substrate for phosphorus removal. Ecological Engineering, 41, 65-69.

Narkis, N. and Meiri, M. (1981) Phosphorus removal by activated alumina. Environmental Pollution Series B, Chemical and Physical, 2(5), 327-343.

Nittami, T., Oi, H., Matsumoto, K. and Seviour, R.J. (2011) Influence of temperature, $\mathrm{pH}$ and dissolved oxygen concentration on enhanced biological phosphorus removal under strictly aerobic conditions. New Biotechnology, 29(1), 2-8.

Nosrati, S., Seifpanahi-Shabani, K. and Karamoozian, M. (2017) Novel polymorphous aluminosilicate nano minerals: Preparation, characterization and dyes wastewater treatment. Korean Journal of Chemical Engineering, 34(9), 2406-2417.

Novak, J.T. and Park, C.M. (2010) The effect of iron and aluminium for phosphorus removal on anaerobic digestion and organic sulfur generation. Water science and Technology, 62(2), 419-426.

Oguz, E. (2005) Sorption of phosphate from solid/liquid interface by fly ash. Colloids and Surfaces A: Physicochemical and Engineering Aspects, 262(1-3), 113-117.

Rahmani-Sani, A., Shan, R.-r., Yan, L.-g. and HosseiniBandegharaei, A. (2017) Response to "Letter to Editor: Minor correction to the thermodynamic calculation using the distribution constant by Shan et al. and Rahmani-Sani et al.". Journal of Hazardous Materials, 325, 367.

Razali, M., Zhao, Y. and Bruen, M. (2007) Effectiveness of a drinking-water treatment sludge in removing different phosphorus species from aqueous solution. Separation and Purification Technology, 55(3), 300-306.

Reitzel, K., Ahlgren, J., Gogoll, A. and Rydin, E. (2006) Effects of aluminum treatment on phosphorus, carbon, and nitrogen distribution in lake sediment: a 31P NMR study. Water Research, 40(4), 647-654.

Reitzel, K., Hansen, J., Andersen, F. Ø., Hansen, K.S. and Jensen, H.S. (2005) Lake restoration by dosing aluminum relative to mobile phosphorus in the sediment. Environmental Science \& Technology, 39(11), 4134-4140.

Reitzel, K., Hansen, J., Jensen, H.S., Andersen, F. $\varnothing$. and Hansen, K.S. (2003) Testing aluminum addition as a tool for lake restoration in shallow, eutrophic Lake Sønderby, Denmark. Hydrobiologia, 506(1-3), 781-787.

Reyes Bahena, J., Robledo Cabrera, A., Lopez Valdivieso, A. and Herrera Urbina, R. (2002) Fluoride adsorption onto $\alpha$-Al2O3 and its effect on the zeta potential at the alumina-aqueous electrolyte interface. Separation Science and Technology, 37(8), 1973-1987.

Rufino, B., Boulc'h, F., Coulet, M.-V., Lacroix, G. and Denoyel, R. (2007) Influence of particles size on thermal properties of aluminium powder. Acta Materialia, 55(8), 2815-2827.

Sansalone, J.J. and Ma, J. (2009) Parametric evaluation of batch equilibria for storm-water phosphorus adsorption on aluminum oxide media. Journal of Environmental Engineering, 135(9), 737-746.

Seviour, R.J., Mino, T. and Onuki, M. (2003) The microbiology of biological phosphorus removal in activated sludge systems. FEMS microbiology reviews, 27(1), 99-127.

Smith, V.H. (2003) Eutrophication of freshwater and coastal marine ecosystems a global problem. Environmental Science and Pollution Research, 10(2), 126-139.

Sohn, S. and Kim, D. (2005) Modification of Langmuir isotherm in solution systems-definition and utilization of concentration dependent factor. Chemosphere, 58(1), 115-123.

Tran, H.N., You, S.-J., Hosseini-Bandegharaei, A. and Chao, H.-P. (2017b) Mistakes and inconsistencies regarding adsorption of contaminants from aqueous solutions: a critical review. Water Research, 120, 88-116.

Tran, H.N., You, S.-J., Nguyen, T.V. and Chao, H.-P. (2017a) Insight into adsorption mechanism of cationic dye onto biosorbents derived from agricultural wastes. Chemical Engineering Communications, 204(9), 1020-1036.

Tzoupanos, N. and Zouboulis, A. (2010) Novel inorganic-organic composite coagulants based on aluminium. Desalination and Water Treatment, 13(1-3), 340-347.

Ugurlu, A. and Salman, B. (1998) Phosphorus removal by fly ash. Environment international, 24(8), 911-918.

Weber, W.J. and Morris, J.C. (1963) Kinetics of adsorption on carbon from solution. Journal of the Sanitary Engineering Division, 89(2), 31-60.

Yopps, J. and Fuerstenau, D. (1964) The zero point of charge of alpha-alumina. Journal of Colloid Science, 19(1), 61-71.

Yuh-Shan, H. (2004) Citation review of Lagergren kinetic rate equation on adsorption reactions. Scientometrics, 59(1), 171177. 